\title{
ENGEVISTA
}

Página da revista: http://www.uff.br/engevista/seer/

\section{Estudo probabilístico das cargas nas estacas de dolfins de amarração e atracação}

\section{Probabilistic study of piles loadings in mooring and berthing dolphins}

\author{
Andre Pereira Ramos ${ }^{1}$ \\ João Paulo Silva Lima ${ }^{2}$ \\ Bolivar Zanella Ribeiro ${ }^{3}$ \\ Mauro de Vasconcellos Real ${ }^{4}$
}

Resumo: Dolfins são estruturas marítimas sujeitas a ações variáveis de difícil previsibilidade. Com isso, para uma análise estrutural segura devem ser consideradas as distribuições estatísticas dessas ações. Neste trabalho, a partir de um modelo estrutural de elementos finitos, empregaram-se os Métodos de Monte Carlo e Latin Hypercube na análise probabilística da estrutura dos dolfins, considerando o efeito da variabilidade dos esforços externos nos valores das reações nas estacas. Para a execução do modelo de elementos finitos e da análise probabilística da estrutura foi utilizado o software ANSYS®. Os resultados mostram que os valores máximos das reações são próximos daqueles previstos nas combinações de cálculo usualmente consideradas no projeto deste tipo de estrutura.

Palavras-chave: Dolfim, elementos finitos, análise probabilística, ANSYS®.

\footnotetext{
${ }^{1}$ FURG - Universidade Federal do Rio Grande

${ }^{2}$ FURG - Universidade Federal do Rio Grande

${ }^{3}$ FURG - Universidade Federal do Rio Grande

${ }^{4}$ FURG - Universidade Federal do Rio Grande
} 
ISSN: $1415-7314$

ISSN online: 2317-6717

Abstract: Mooring dolphins are maritime structures subject to variable loads with difficult predictability. In order to develop a safe structural analysis, the statistical distributions of such actions must be considered. In this article, a probabilistic analysis of these structures is performed starting from a structural model based on the finite element method. The analisys uses Monte Carlo method and Latin Hypercube sampling method, considering the effect of load variability on the piles vertical reaction forces. The software ANSYS® was used in the elaboration of the finite element model and the probabilistic analysis of the structures. The results show that maximum reactions values are similar to those provided by the load combinations usually considered in the design of this type of structure.

Keywords: Mooring dolphins, ANSYS®, finite elements, probabilistic design. 


\section{Introdução}

Dolfins são estruturas marítimas ou portuárias discretas, que desempenham funções de amarração e atracação de embarcações. São bastante frequentes em terminais de minérios, mas também são encontrados em terminais diversos e estaleiros (Alfredini \& Arasaki, 2009).

De acordo com Tsinker (2004), tais estruturas são dotadas de cabeços para amarração e/ou ganchos de liberação rápida, além de outros meios de amarrações para lidar com a ancoragem de um navio. Em alguns casos, os dolfins são equipados com defensas para proteção contra impactos de atracação das embarcações.

Ainda segundo Tsinker (2004), os dolfins são estruturas geralmente constituídas por laje de concreto armado apoiada sobre estacas metálicas ou em concreto armado ou protendido. Além disso, existem dois principais tipos de estruturas utilizados para a execução de dolfins: rígidas e flexíveis. Estruturas rígidas defletem uma parcela muito pequena da carga de projeto, sendo assim a energia de atracação de grandes navios é absorvida por um sistema de para-choques resistente. Já dolfins flexíveis defletem sob impacto, e tanto a estrutura como as defensas resilientes absorvem a energia do impacto.

Do ponto de vista da sua utilização, os dolfins podem ser classificados como sendo de amarração ou de atracação. Os dolfins de amarração, além das cargas de peso próprio e sobrecarga acidental, recebem esforços oriundos dos cabos de amarração das embarcações a eles fixadas. Esses esforços agem sobre os dolfins geralmente via cabeços de amarração, peças metálicas construídas exclusivamente para receber as amarras das embarcações. Devido à sua configuração geométrica, os cabeços também transferem momentos fletores à estrutura dos dolfins, uma vez que existem excentricidades verticais do ponto de aplicação das forças aos eixos de cálculo da estrutura. As ações de amarração são provenientes da ação dos ventos, ondas e correntes marítimas que agem sobre as embarcações. São esforços variáveis, de difícil previsibilidade, e cujas intensidades e distribuições estatísticas são de fundamental importância para o dimensionamento seguro das estruturas.

Essa questão tem ainda mais relevância em regiões de ocorrência de ventos, correntes e ondas de intensidades elevadas, como a região do Porto do Rio Grande. Como exemplo, retoma-se fato sucedido nessa cidade no ano de 2013, quando a ocorrência de ventos de elevada intensidade fez com que se rompessem as amarras da Plataforma P-58, então em construção na cidade, deixando a mesma à deriva no Canal do Porto. No mesmo evento, a plataforma ainda se chocou contra outra plataforma também em construção na cidade, a P-63. Além dos prejuízos aos projetos, a situação colocou em risco a vida de diversos trabalhadores.

Os dolfins de atracação, por sua vez, além do seu peso próprio e sobrecarga acidental recebem esforços oriundos do impacto proveniente da acostagem das embarcações. Os esforços de impacto agem sobre os dolfins via defensas de atracação, elementos de interface entre as embarcações e as estruturas de acostagem que visam proteger ambas dos esforços de impacto das 
atracações, através da absorção da energia cinética advindas das embarcações (Alfredini \& Arasaki, 2009). Esses esforços também são variáveis, porém de estimativas mais acessíveis, já que têm por base as características geométricas dos navios, deslocamentos e características da manobra de acostagem, como as velocidades e ângulos de aproximação, entre outros. Trata-se de esforços importantes na análise estrutural dos dolfins, e seu entendimento é de fundamental importância no dimensionamento adequado dessas estruturas.

De acordo com Araújo (2010), a segurança estrutural em projetos correntes é obtida através da adoção dos coeficientes parciais de ponderação das resistências do concreto - $\gamma_{c}$ e do aço - $\gamma_{s} e$ das ações $-\gamma_{f}$, e da verificação da relação $R_{d} \geq S_{d}$, onde $R_{d}$ representa os esforços resistentes nos estados limites últimos considerados e $S_{\mathrm{d}}$ os esforços solicitantes de projeto. Esse método, mesmo levando em conta as características probabilísticas do problema, acaba por tratar algumas questões de forma determinística, como a falta de referência às variações das resistências dos materiais no domínio da estrutura, as condições de vinculação e as posições das cargas atuantes na estrutura, por exemplo. Com isso, observa-se que se trata de um método semiprobabilístico.

Araújo (2010) também comenta que a adoção do método dos coeficientes parciais de ponderação, apesar de ser conveniente do ponto de vista prático, não é suficiente para que se tenha uma ideia clara a respeito do nível de segurança obtido no projeto, uma vez que a segurança da estrutura depende do seu comportamento frente às ações, o que envolve uma interdependência das diversas variáveis aleatórias. Uma avaliação consistente do nível de segurança requer o cálculo da probabilidade de o estado limite último ser alcançado.

Podem-se quantificar as incertezas inerentes aos esforços atuantes através de uma análise probabilística da estrutura, a qual permite que cada elemento da população tenha uma chance conhecida e diferente de zero de ser selecionada para compor a amostra (Mattar, 1992). Para realizar tal análise, foram aplicados o método de Monte Carlo e o método do Latin Hypercube. Essas duas metodologias permitem estudar o efeito da variabilidade de determinados parâmetros e que têm ganhado destacada importância em certas áreas da Engenharia Civil (Gomes, 2013). Dessa forma, pode-se informar um coeficiente de variação para cada variável e posteriormente calcular diferentes combinações de esforços.

No âmbito da normatização e regulamentação da análise probabilística, diversos órgãos vêm dedicando atenção especial ao assunto, dentre os quais se destaca o JCSS - Joint Committee on Structural Safety com o seu Código de Modelos Probabilísticos, importante estudo que aglutina normas voltadas à análise probabilística de estruturas. Tal estudo apresenta a base teórica da análise probabilística, bem como modelos para carregamentos e resistências diversos, incluindo aqueles para variabilidade de cargas de peso próprio e devidas ao vento em estruturas.

Dentro desse contexto, o objetivo deste trabalho é realizar uma análise probabilística dos esforços nas estacas em dolfins de amarração e atracação. Nesse sentido, a partir da variação de parâmetros dos materiais e das ações que incidam na estrutura serão analisadas as distribuições 
estatísticas dos esforços de reação nesses elementos. Para as estacas mais carregadas em cada caso será verificada a probabilidade de ocorrência de esforços superiores aos característicos, que são aqueles que levariam, através da aplicação dos coeficientes parciais de ponderação, aos esforços de cálculo utilizados no dimensionamento da estrutura.

As estruturas analisadas tiveram como modelo o projeto de três dolfins previstos para o Cais Norte do Estaleiro Rio Grande, em Rio Grande/RS, sendo um de amarração e dois de atracação, sendo estes idênticos. Desse projeto foram retirados os modelos geométricos, os materiais utilizados e os carregamentos externos característicos atuantes nas estruturas.

\section{Metodologias}

\subsection{Análise determinística - método dos elementos finitos}

Em análises estruturais, diversas situações podem ser representadas por um modelo adequado usando um número finito de componentes bem definidos. São os modelos discretos. Em outras, a subdivisão é contínua e indeterminada, fazendo com que o problema somente possa ser definido usando a matemática infinitesimal, o que conduz à necessidade de resolução das equações diferenciais do problema para um número infinito de elementos. Esses modelos são chamados de contínuos. Para superar a difícil tratabilidade dos modelos realísticos contínuos, diversos métodos de discretização foram propostos por engenheiros e matemáticos ao longo do século XX. Todos esses métodos envolvem uma aproximação do tipo que, tão próxima quanto desejada, persegue a solução contínua à medida que o número de variáveis discretas aumenta (Zienkiewicz, 1977).

Entre os diversos métodos existentes destaca-se o Método dos Elementos Finitos, largamente utilizado no campo da engenharia estrutural. Segundo Martha (2010), nesse método o modelo discreto é obtido pela subdivisão do domínio contínuo da estrutura em subdomínios, chamados de elementos finitos. Tais elementos possuem formas simples (em modelos planos, por exemplo, utilizam-se geralmente triângulos ou quadriláteros). Essa subdivisão é denominada malha de elementos finitos, e os parâmetros que representam a solução discreta são valores de deslocamentos nos nós (vértices) da malha.

Neste trabalho, a construção dos modelos computacionais foi desenvolvida com o software ANSYS®, que utiliza o Método dos Elementos Finitos para análises estruturais, entre outras, apresentando uma enorme variedade de tipos de análises e de elementos, entre outras definições. Para construção dos modelos computacionais foram utilizados dois tipos de elementos, cada um deles apropriados respectivamente à parte da estrutura simulada, conforme representado na figura 1. 


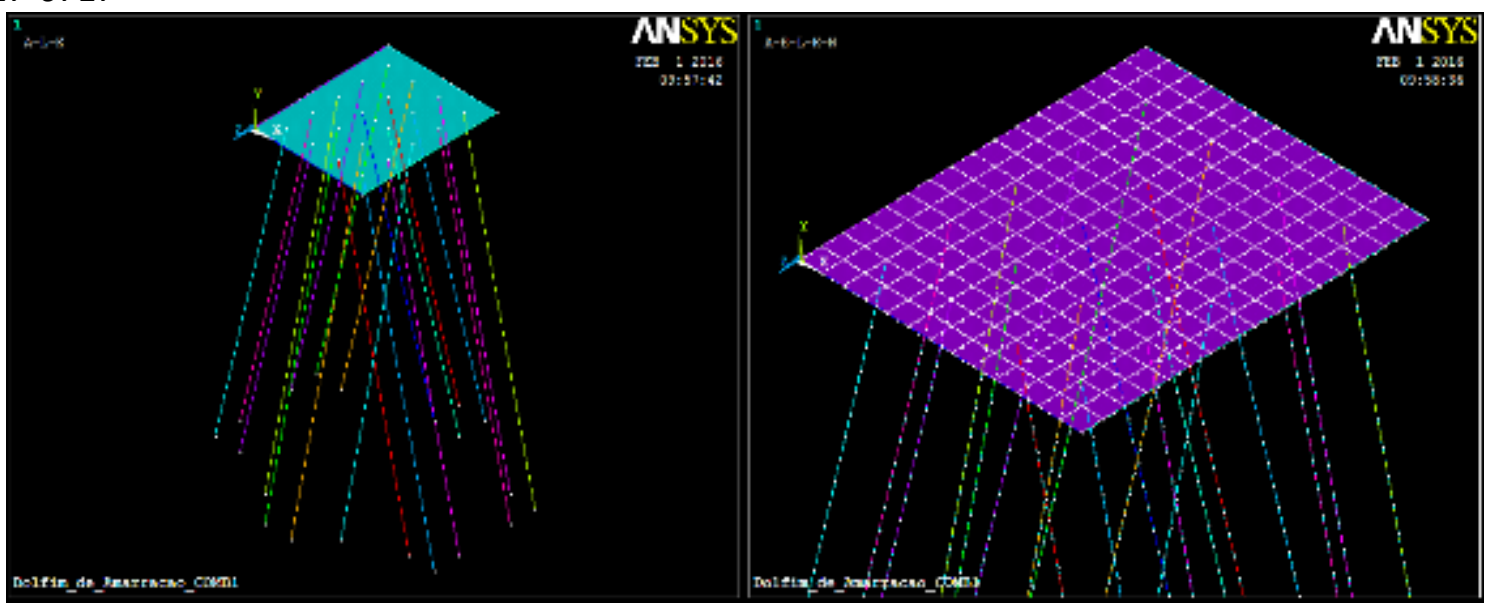

Figura 1: Modelo computacional do dolfim de amarração (esquerda), e a sua discretização com a malha de elementos finitos.

Para as estacas metálicas, constituídas cada uma por dois perfis $\mathrm{W}$ soldados, foram utilizados os elementos do tipo Beam 44. Trata-se de elemento linear (uniaxial) com capacidades de esforços axiais, torção e flexão. Tal elemento é definido por dois nós, possuindo seis graus de liberdade em cada um deles: translações e rotações em x, y e z, e seus parâmetros de entrada consistem nos elementos geométricos que descrevem os elementos lineares a serem modelados: área da seção transversal, momentos de inércia principais, posição e distância do centroide até as fibras extremas, e as constantes de cisalhamento. O elemento Beam 44 e seus parâmetros são apresentados figura 2 .
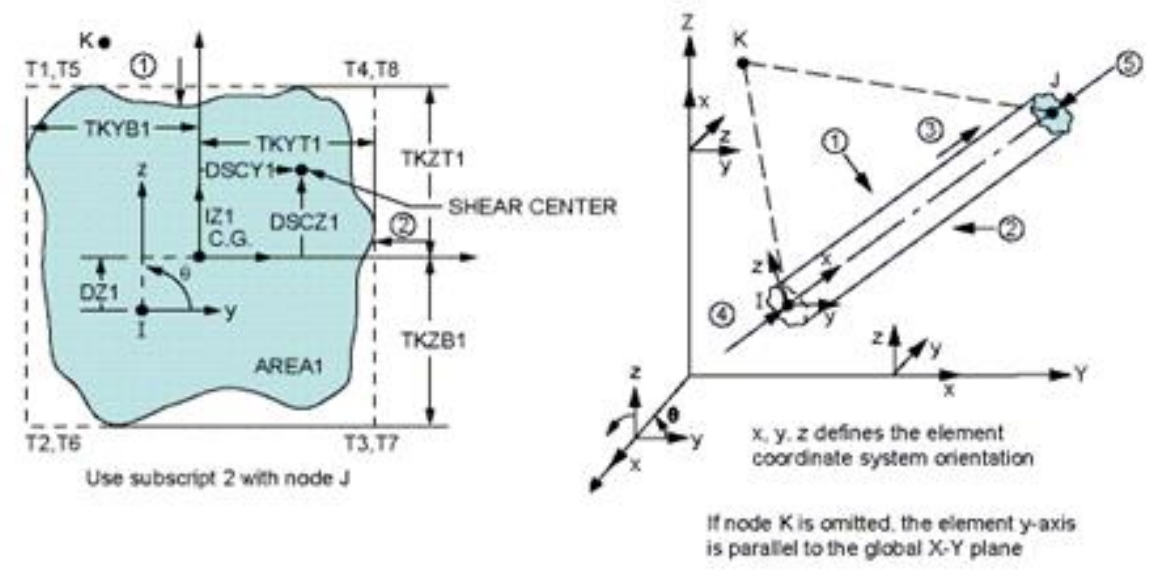

Figura 2: Parâmetros geométricos dos elementos Beam 44. (Fonte: ANSYS User's Manual, 2005).

Para a laje de concreto armado foram utilizados os elementos do tipo Shell 93. Trata-se de elemento de placa com capacidades de plasticidade, enrijecimento, grandes deflexões e deformações. A deformação possui forma quadrática em ambas as direções no plano do elemento. Os elementos podem ter forma quadrática ou triangular com oito ou seis nós, respectivamente, sendo que cada nó possui seis graus de liberdade: translações e rotações em x, y e z. Seus parâmetros de entrada consistem nas espessuras em cada um dos vértices do elemento, bem como o 
ângulo de rotação do elemento ao longo do eixo x. O elemento Shell 93 e seus parâmetros são apresentados na figura 3.

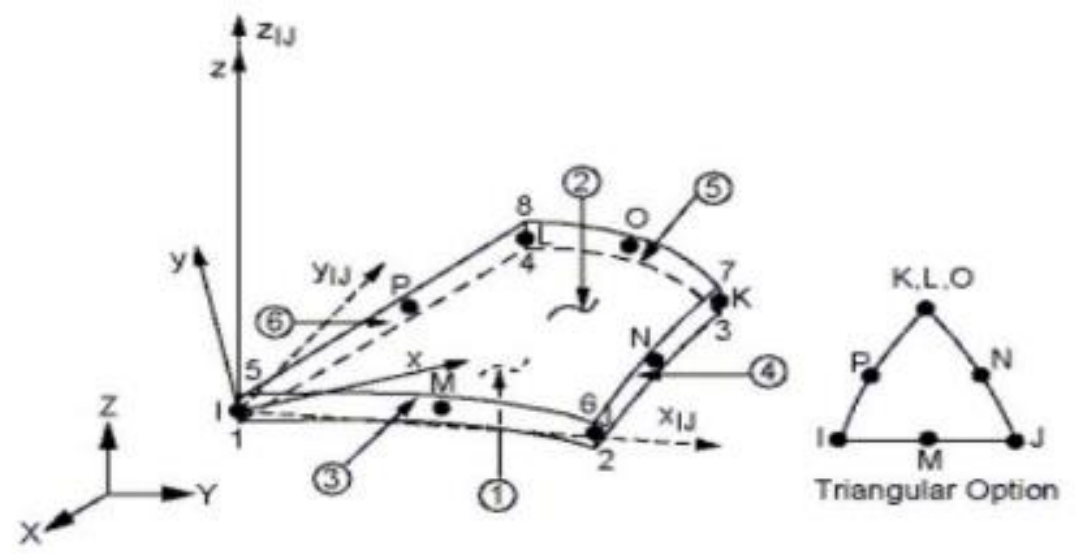

Figura 3: Parâmetros geométricos dos elementos Shell 93. (Fonte: ANSYS User's Manual, 2005).

\subsection{Análise probabilística}

Para alcançar os objetivos deste trabalho, deve-se analisar a influência da variação das cargas atuantes na estrutura verificando-se os esforços resultantes na base das estacas. Para isso, todos os carregamentos presentes - peso próprio, sobrecarga, forças de amarração e forças de atracação - foram tratados como variáveis. Em seguida, foi atribuído à cada carga um coeficiente de variação que representa a razão entre o desvio padrão e a média de uma distribuição de valores (Hendricks \& Robey, 1936). Tais coeficientes normalmente são retirados de normas técnicas, artigos e outros estudos acadêmicos a respeito das respectivas cargas.

\subsubsection{Variáveis do estudo}

Uma vez definidas as variáveis de estudo, para cada uma foi atribuído um coeficiente de variação, que representa a oscilação de um valor em relação à média, conforme a seguinte expressão (Correa, 2003):

$$
\operatorname{CoV}=\frac{\sigma}{\mu}
$$

onde $\sigma$ é o desvio padrão e $\mu$ é a média.

Tais variáveis possuem uma distribuição normal. Portanto, para determinarmos os valores característicos das variáveis aleatórias para os quais a probabilidade de serem ultrapassados seja de $5 \%$, é válida a seguinte relação:

$$
\mathrm{F}_{\mathrm{k}}=\mathrm{F}_{\mathrm{m}}+1,65 * \sigma
$$


onde $F_{k}$ é o valor característico e $F_{m}$ é o valor médio.

Logo, para considerar o coeficiente de variação das cargas no valor característico, tem-se que:

$$
\mathrm{F}_{\mathrm{k}}=\mathrm{F}_{\mathrm{m}} *(1+1,65 * \mathrm{CoV})
$$

Para o caso do peso próprio e da sobrecarga, os coeficientes de variação são menores e foram estimados com base em trabalhos semelhantes.

Já para as forças de amarração e impacto ou atracação, tais coeficientes são de difícil determinação, em função da complexidade dos ensaios necessários para encontrar resultados. Essa situação é consequência da influência dos elementos da natureza nas forças, tais como ventos e correntes, além das condições próprias de cada região onde se encontra a estrutura: calado, tipo de embarcação, tipo de amarração, presença de molhes ou barreiras naturais, entre outros. Desta forma, o ideal seria que cada região portuária obtivesse seus próprios dados estatísticos em busca de melhores condições de projeto para suas estruturas portuárias.

Para os fins deste trabalho, tais coeficientes foram considerados como sendo os mesmos obtidos para as forças de vento segundo Versteegt (2013). Recomenda-se que mais estudos sejam realizados em busca de valores mais precisos para esses coeficientes. A tabela 1 mostra um resumo de todas as variáveis existentes neste estudo e seus respectivos coeficientes de variação:

Tabela 1: Coeficientes de variação das variáveis utilizadas na análise probabilística.

\begin{tabular}{ccc}
\hline Variável & Unidade & $\mathrm{CoV}$ \\
\hline Peso Próprio & $\mathrm{kN} / \mathrm{m}^{2}$ & 0,1 \\
Sobrecarga & $\mathrm{kN} / \mathrm{m}^{2}$ & 0,2 \\
Amarração & $\mathrm{kN} / \mathrm{m}^{2}$ & 0,4 \\
Atracação & $\mathrm{kN} / \mathrm{m}^{2}$ & 0,3 \\
\hline
\end{tabular}

Para o presente estudo, as variáveis acima foram distribuídas em quatro combinações de acordo com as possibilidades de utilização dos dolfins analisados. Em ambos os casos, podemos ter o dolfim possuindo ou não sobrecarga acidental sobre a laje. Dessa forma, a tabela 2 apresenta as quatro combinações que foram levadas em conta durante a realização do estudo:

Tabela 2: Combinações de cargas consideradas.

\begin{tabular}{ccc}
\hline Combinação & Ações presentes (Variáveis) & Dolfim \\
\hline COMB 1 & Peso Próprio + Sobrecarga & Amarração \\
COMB 2 & Peso Próprio + Sobrecarga + & Amarração \\
COMB 3 & Amarração & Atracação \\
COMB 4 & Peso Próprio + Sobrecarga & Atracação + Sobrecarga + \\
\hline
\end{tabular}




\subsubsection{O método de monte carlo e o latin hypercube}

Atualmente, a capacidade de processamento dos computadores tornou o processo de simulação probabilística relativamente simples. Além disso, softwares cada vez mais amigáveis permitem a realização de tais simulações mesmo que o usuário tenha apenas conhecimentos básicos na área de probabilidade e estatística (Veiga, 2008).

Neste cenário, o método de Monte Carlo é considerado uma ferramenta poderosa no desenvolvimento de análises probabilísticas. O método consiste basicamente em realizar inúmeras repetições da simulação, usando em cada uma delas um valor particular das variáveis aleatórias do problema, dentro da sua distribuição de probabilidade (Neves, 2004). Desta maneira, para cada combinação de carregamentos, cada uma das variáveis assume um valor aleatório dentro de um intervalo pré-determinado. Realizando um determinado número de simulações, tem-se o mesmo valor de resultados diferentes para uma mesma combinação.

Ainda segundo Neves (2004), embora fosse bastante preciso o método de Monte Carlo não representava um método realístico de solução antes do desenvolvimento de computadores velozes e, mesmo assim, ainda requer um número elevado de simulações para atingir a convergência. Porém, nem sempre é possível ou desejável aumentar-se o número de simulações em busca de melhores resultados, uma vez que o número mínimo de simulações necessárias para avaliar a incerteza do método não é um valor consensual (Gomes, 2013).

Nestes casos, o método Latin Hypercube pode ser escolhido no intuito de agilizar a convergência com um número reduzido de simulações. Este método distribui os valores das variáveis aleatórias de forma que cada valor único apareça em apenas uma única combinação possível. De fato, como será mostrado neste trabalho, a utilização deste método reduziu consideravelmente o número de simulações necessário para que seja atingido ponto satisfatório de convergência dos resultados.

\subsubsection{Probabilistic design - ANSYS $®$}

Em busca de um equilíbrio entre a otimização técnica e financeira de obras de engenharia e a existência da incerteza e da aleatoriedade a que tais obras estão sujeitas, o ANSYS® Probabilistic Design System (PDS), lançado pela ANSYS Inc. se mostra uma ferramenta extremamente útil. (Reh et al., 2006).

Presente no Software ANSYS desde o ano 2000, o PDS permite que o método de Monte Carlo seja aplicado a um estudo probabilístico como o proposto neste trabalho. Além disso, possibilita que as amostras sejam retiradas de modo direto ou através do método Latin Hypercube, afim de reduzir o tempo de processamento necessário.

Por último, é necessário selecionar uma semente, ou seed, para iniciar a simulação. A opção recomendada normalmente é iniciar sempre com o valor 123457. Desta maneira, caso a simulação tenha que ser repetida, os resultados obtidos serão os mesmos. 


\section{Resultados e discussão}

\subsection{Descrição dos dolfins analisados}

Os dolfins de amarração e atracação analisados neste trabalho são constituídos de uma laje horizontal de concreto armado disposta sobre vinte estacas metálicas inclinadas em rampa de 1:4. Afigura5apresenta o arranjo geométrico do dolfim de amarração, semelhante ao de atracação.

$\mathrm{O}$ dolfim de amarração possui laje de dimensões de $8,00 \mathrm{~m} \times 6,50 \mathrm{~m}$ (eixos $\mathrm{z}$ e $\mathrm{x}$, respectivamente, na figura 5), enquanto que o dolfim de atracação possui laje de 9,00m x 6,50m. Ambas as lajes possuem espessuras de 1,5 m e são constituídas de concreto com $\mathrm{f}_{\mathrm{ck}}$ de $40 \mathrm{MPa}$.

Já as estacas metálicas são compostas cada uma por dois perfis W610x125 soldados lado a lado pelos seus flanges. Os perfis em questão podem ser encontrados no catálogo da Empresa GERDAU S. A., fabricante de barras e perfis estruturais de grande inserção no mercado brasileiro. $\mathrm{O}$ arranjo final das seções transversais das estacas após efetuadas as soldas nos flanges dos perfis é mostrado na figura 4.

A tabela 3 apresenta as características geométricas e os parâmetros dos materiais empregados nas estruturas.

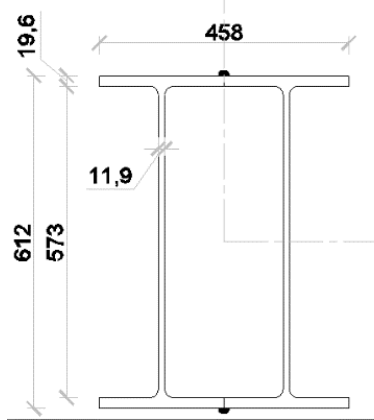

Figura 4: Seção transversal típica das estacas metálicas.

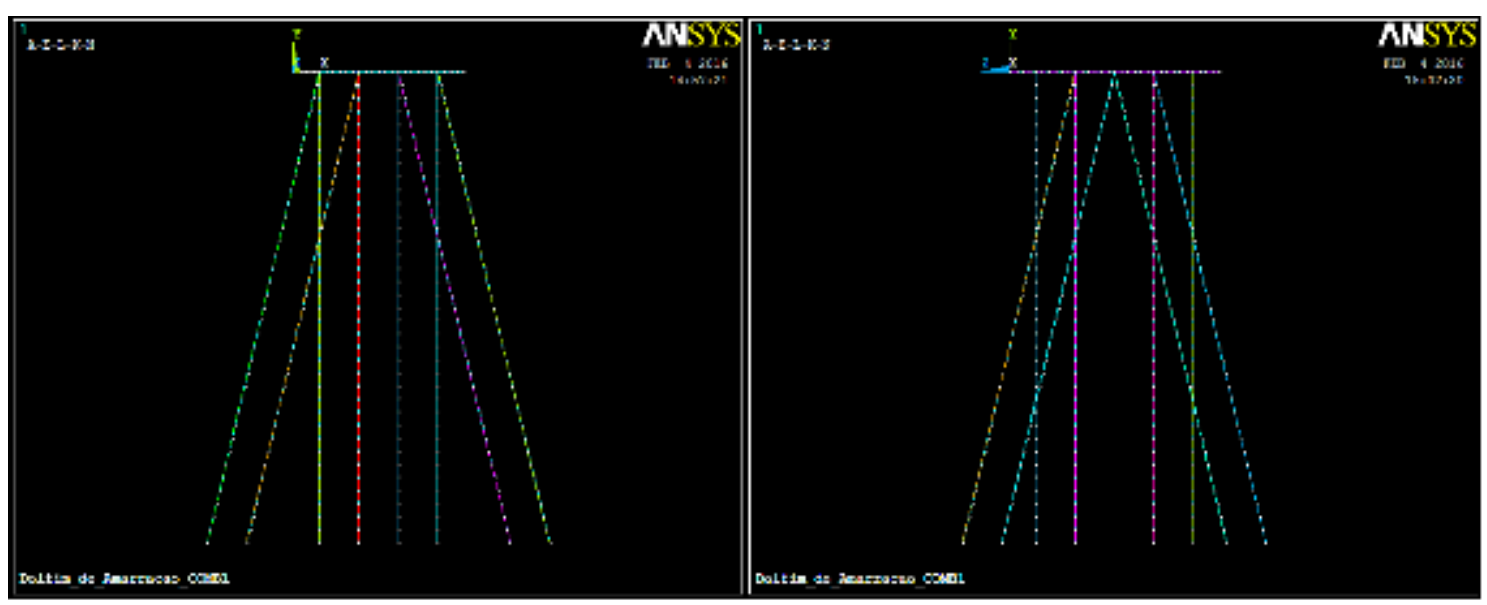




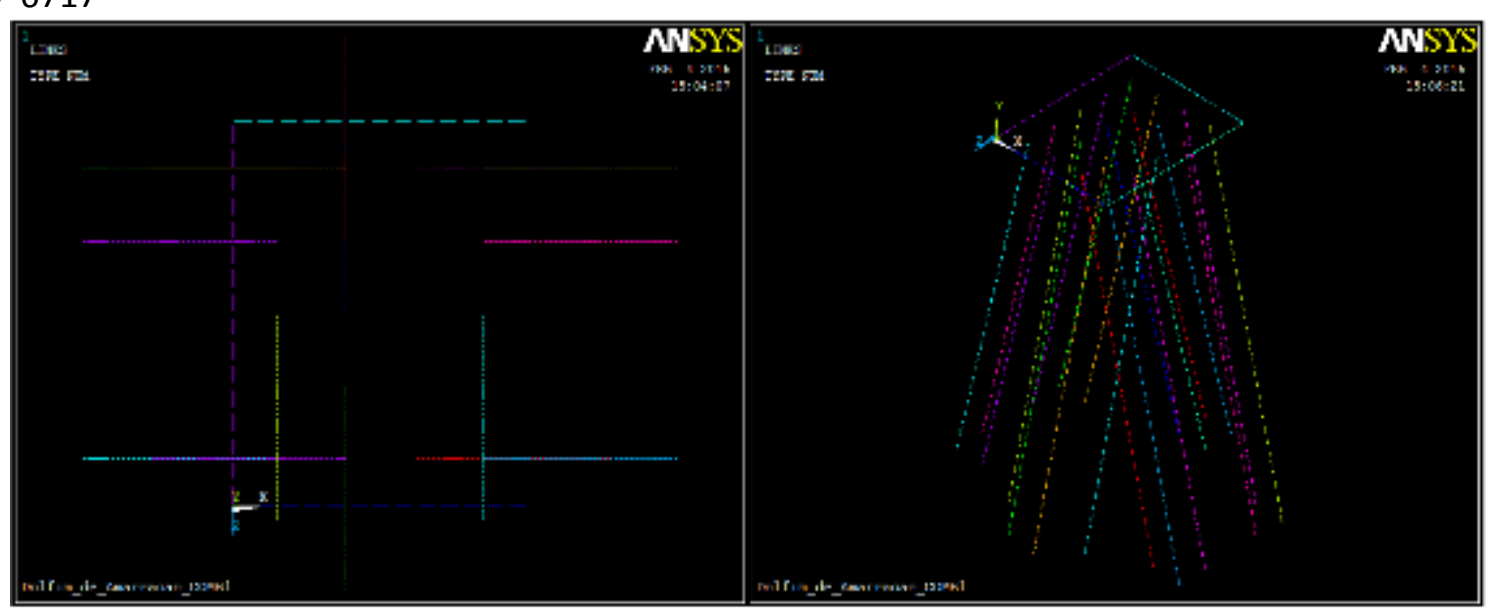

Figura 5: Detalhamento da estrutura estudada. (a) vista frontal, (b) vista lateral, (c) vista em planta e (d) vista em perspectiva do dolfim de amarração.

Tabela 3: Parâmetros geométricos e dos materiais utilizados nas estruturas dos dolfins analisados.

\begin{tabular}{|c|c|}
\hline \multicolumn{2}{|c|}{ Laje em Concreto Armado } \\
\hline$t(\mathrm{~m})$ & 1,5 \\
\hline$f_{c k}(\mathrm{MPa})$ & 40 \\
\hline$E(\mathrm{GPa})$ & 30104,88 \\
\hline$v$ & 0,3 \\
\hline \multicolumn{2}{|c|}{ Estacas Metálicas } \\
\hline$h(\mathrm{~mm})$ & 612 \\
\hline$b(\mathrm{~mm})$ & 458 \\
\hline$L_{\text {calc }}(\mathrm{m})$ & 17,63 \\
\hline$t_{a b a}(\mathrm{~mm})$ & 11,9 \\
\hline$t_{\text {alma }}(\mathrm{mm})$ & 19,6 \\
\hline$A\left(\mathrm{~m}^{2}\right)$ & 0,032 \\
\hline$I_{y}\left(\mathrm{~m}^{4}\right)$ & 0,001983 \\
\hline$I_{z}\left(\mathrm{~m}^{4}\right)$ & 0,000498 \\
\hline$J\left(\mathrm{~m}^{4}\right)$ & 0,002519 \\
\hline
\end{tabular}

Os dois tipos de estruturas analisadas possuem as mesmas condições de apoio e de ligação dos elementos estruturais. Todas as estacas de ambos os modelos foram consideradas engastadas na sua base.

O peso próprio da estrutura e a sobrecarga acidental foram considerados como forças distribuídas aplicadas na área da laje. Em ambas as estruturas os seus valores por unidade de área são idênticos.

Nas estruturas correntes, os esforços provenientes das amarras das embarcações são geralmente aplicados aos cabeços de amarração. Para efeito da modelagem computacional da estrutura, esses esforços são transferidos para a laje onde os cabeços são fixados. Essa transferência conduz ao surgimento de momentos fletores na estrutura, calculados com forças atuantes 
multiplicadas pela distância vertical das mesmas até o eixo de cálculo da laje. A figura 6 ilustra essa situação.
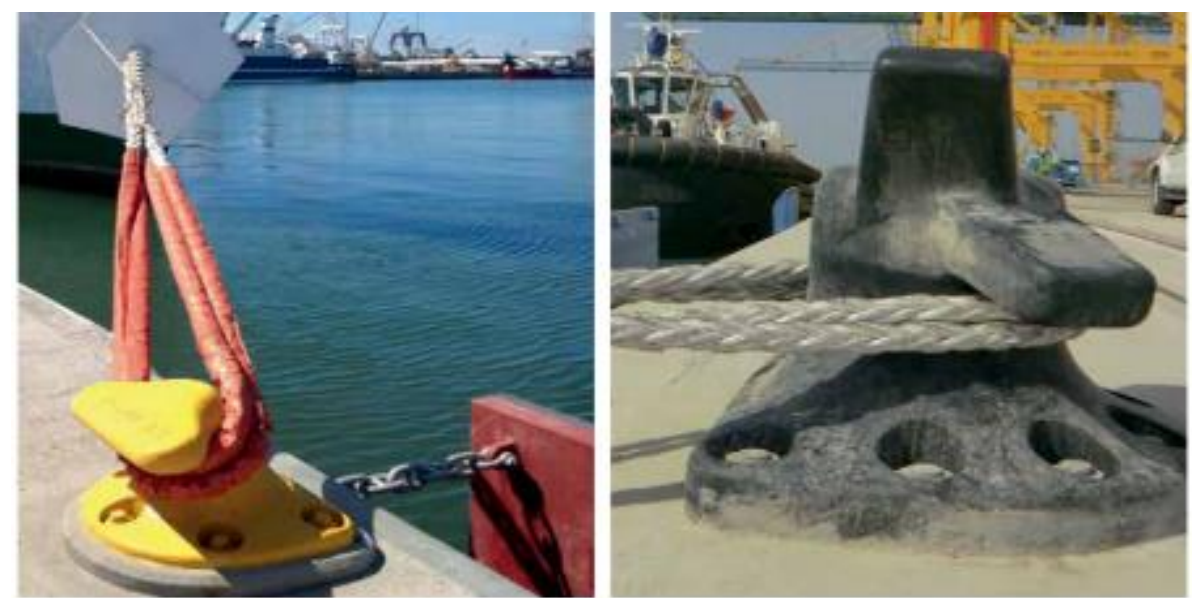

Figura 6. Cabeços de amarração (Fonte: Fender Team, Catálogo de Produtos).

Os esforços de impacto nas estruturas de acostagem são aplicados nas defensas de atracação. A implementação desses esforços no modelo computacional também deve considerar a transferência de momentos para a estrutura, uma vez que o ponto de aplicação das cargas possui excentricidade em relação ao eixo de referência da laje. A figura 7 apresenta defensas utilizadas em estruturas portuárias.

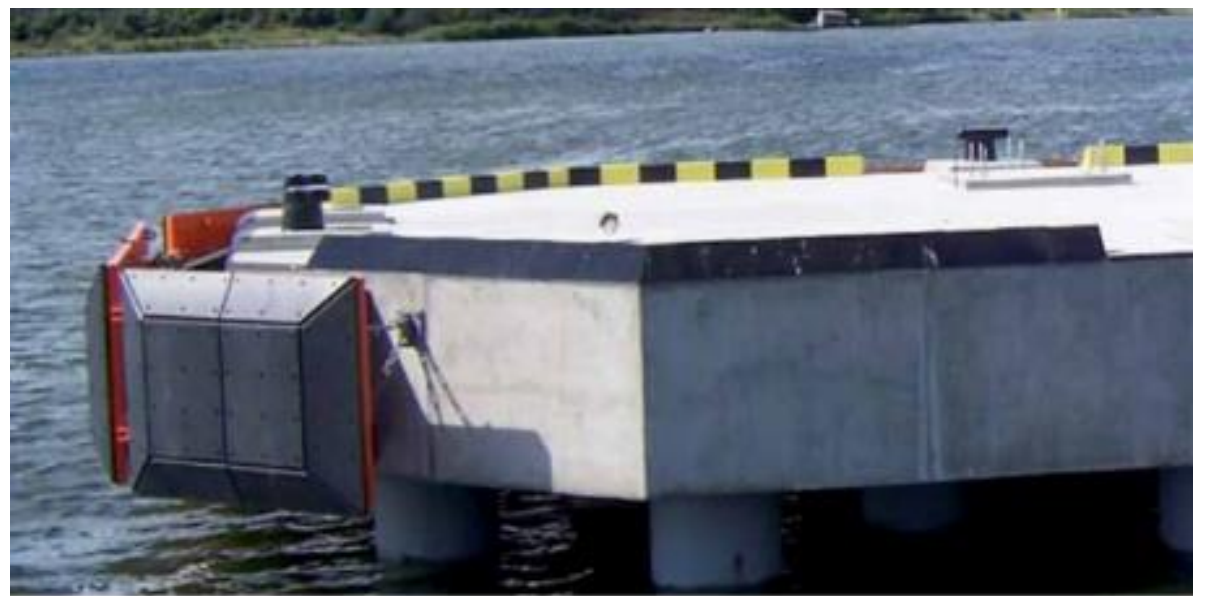

Figura 7. Defensa utilizada em dolfim de atracação (Fonte: Fender Team, Catálogo de Produtos).

Conforme exposto, as situações acima mencionadas conduzem à aplicação de forças e momentos nas estruturas analisadas. A figura 8 apresenta o resultado da implementação dessas ações nos modelos computacionais gerados para cada dolfim, com as forças representadas na cor vermelha e os respectivos momentos na cor azul.

Sob o ponto de vista da análise probabilística, todas as variáveis consideradas foram assumidas como possuindo distribuição normal (Gaussiana). Essas variáveis representam as cargas características atuantes nas estruturas. Os valores característicos das ações de peso próprio e 
sobrecarga acidental foram assumidos como os próprios valores médios das suas distribuições. Já os esforços característicos de amarração e atracação foram assumidos como aqueles cuja probabilidade de serem ultrapassados é de 5\%, valendo para esses a seguinte relação.

$$
\mathrm{F}_{\mathrm{m}}=\frac{\mathrm{F}_{\mathrm{k}}}{(1+1,65 * \mathrm{CoV})}
$$

A tabela 4 apresenta os esforços considerados na análise probabilística das estruturas em questão.

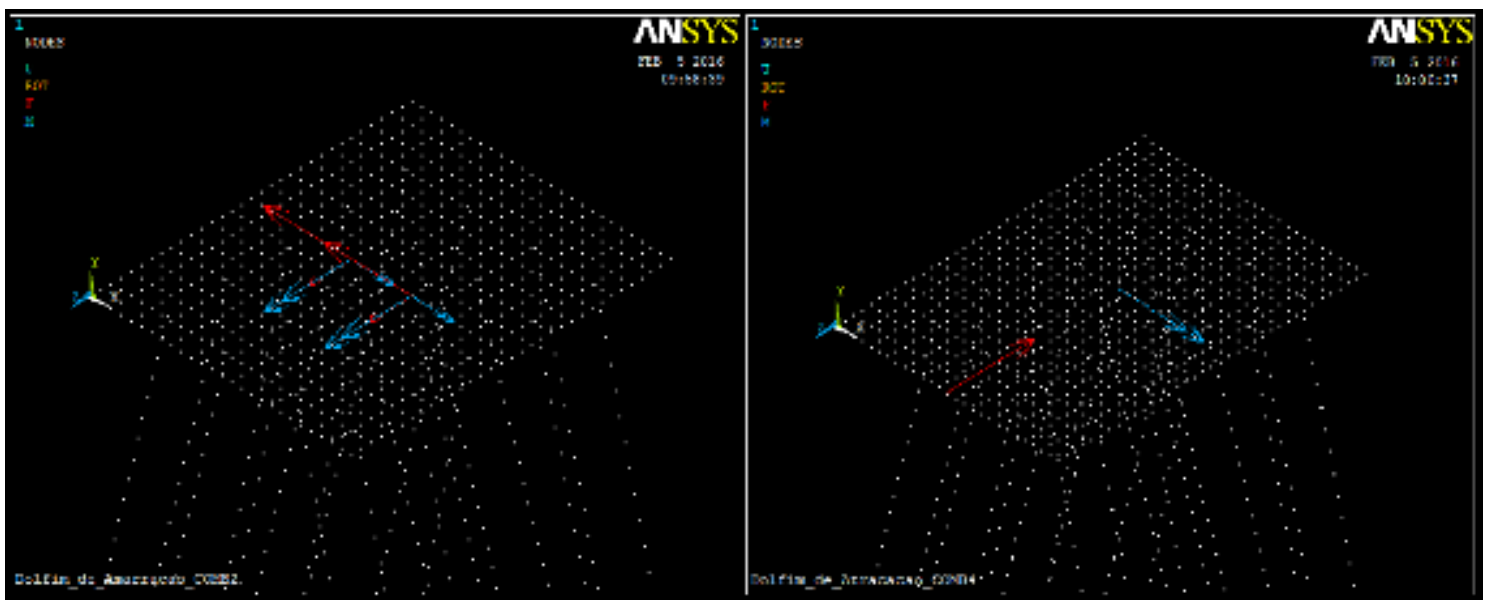

Figura 8: Esforços de amarração (esquerda) e atracação (direita) aplicados aos respectivos modelos computacionais.

Tabela 4: Esforços considerados na análise probabilística da estrutura.

\begin{tabular}{ccccc}
\hline Ação & Unidade & $\begin{array}{c}\text { Esforço } \\
\text { Característico }\end{array}$ & CoV & $\begin{array}{c}\text { Esforço } \\
\text { Médio }\end{array}$ \\
\hline Peso Próprio & $\mathrm{kN} / \mathrm{m}^{2}$ & 54,54 & 0,10 & 54,54 \\
Sobrecarga Acidental & $\mathrm{kN} / \mathrm{m}^{2}$ & 5,00 & 0,20 & 5,00 \\
Amarração $-\mathrm{F}_{\mathrm{x}}$ & $\mathrm{kN}$ & $-1280,00$ & 0,40 & $-771,08$ \\
Amarração $-\mathrm{F}_{\mathrm{z}}$ & $\mathrm{kN}$ & 640,00 & 0,40 & 385,54 \\
Amarração $-\mathrm{M}_{\mathrm{x}}$ & $\mathrm{kN} . \mathrm{m}$ & 1241,60 & - & 747,95 \\
Amarração $-\mathrm{M}_{\mathrm{z}}$ & $\mathrm{kN} . \mathrm{m}$ & $-2483,20$ & - & $-1495,90$ \\
Impacto $-\mathrm{F}_{\mathrm{z}}$ & $\mathrm{kN}$ & $-901,00$ & 0,30 & $-602,68$ \\
Impacto $-\mathrm{M}_{\mathrm{x}}$ & $\mathrm{kN} . \mathrm{m}$ & $-1081,20$ & - & $-723,21$ \\
\hline
\end{tabular}

\subsection{Convergência de malha do modelo de elementos finitos}

Segundo Teixeira et al. (2009), os erros de aproximação, inerentes aos métodos numéricos, recebem grandes parcelas referentes ao erro devido à discretização do domínio computacional, ou, em outras palavras, ao erro devido ao nível de refinamento da malha adotado. Pensando nisso, realizou-se um teste de independência da malha. Tal análise consiste em determinar a quão refinada a malha deve estar para que não acarrete erros significativos nos resultados obtidos. 
Para a realização do teste foi considerado um modelo de análise baseado em diferentes combinações de carregamentos. O teste consiste na constante divisão do modelo em elementos finitos sendo que, à medida que se aumenta o número de divisões, mais refinada se torna a malha. Fez-se o refinamento com elementos quadrados com as dimensões laterais $\mathrm{L}$ iguais a 0,5, 0,25, 0,125 e $0,0625 \mathrm{~m}$.

Os testes de refinamento de malha feitos para diferentes tipos de elementos possuem um critério de parada no qual se verifica o erro relativo entre o valor da resposta requerida observada para uma condição de tamanho de elemento e o valor obtido para a condição de tamanho de elemento subsequente. No caso em estudo, o valor utilizado como parâmetro do teste de refinamento de malha foi a reação vertical na estaca de número 1.

Foi adotado o elemento de tamanho $0,5 \mathrm{~m}$, visto que este tamanho de elemento já torna os resultados das análises satisfatórios devido ao pequeno valor de variação percentual do erro relativo de tal elemento com seu posterior, para todas as quatro combinações analisadas. As tabelas 5 e 6 apresentam os resultados dos testes de independência de malha.

De acordo com as tabelas 5 e 6 , as figuras 9 e 10 apresentam os resultados dos testes de independência de malha na forma de gráficos.

Tabela 5: Teste de independência de malha para as combinações 1 e 2

\begin{tabular}{cccccc}
\hline Tamanho & Combinação 1 & \multicolumn{2}{c}{ Combinação 2 } & \multicolumn{2}{c}{ Variação Percentual } \\
\cline { 3 - 6 } $\begin{array}{c}\text { Elemento } \\
(\mathrm{m})\end{array}$ & $\begin{array}{c}\text { Número de } \\
\text { Elementos }\end{array}$ & $\begin{array}{c}\text { Reação Vertical } \\
\text { Estaca } 1(\mathrm{kN})\end{array}$ & $\begin{array}{c}\text { Reação Vertical } \\
\text { Estaca } 1(\mathrm{kN})\end{array}$ & $\begin{array}{c}\text { Comb. } \\
1\end{array}$ & $\begin{array}{c}\text { Comb. } \\
2\end{array}$ \\
\hline 0,5 & 928 & 507,75 & 520,76 & $0,3 \%$ & $0,3 \%$ \\
0,25 & 2252 & 506,12 & 519,13 & $0,1 \%$ & $0,1 \%$ \\
0,125 & 6168 & 505,55 & 518,56 & $0,0 \%$ & $0,0 \%$ \\
0,0625 & 18972 & 505,40 & 518,41 & - & - \\
\hline
\end{tabular}

Tabela 6: Teste de independência de malha para as combinações 3 a 4

\begin{tabular}{cccccc}
\hline \multirow{2}{*}{$\begin{array}{c}\text { Tamanho } \\
\text { do }\end{array}$} & Número de & Combinação 3 & \multicolumn{2}{c}{ Combinação 4 } & \multicolumn{2}{c}{ Variação Percentual } \\
\cline { 3 - 6 } $\begin{array}{c}\text { Elemento } \\
(\mathrm{m})\end{array}$ & Elementos & $\begin{array}{c}\text { Reação Vertical } \\
\text { Estaca 1 } \\
(\mathrm{kN})\end{array}$ & $\begin{array}{c}\text { Reação Vertical } \\
\text { Estaca 1 } \\
(\mathrm{kN})\end{array}$ & $\begin{array}{c}\text { Comb. 3 } \\
\text { Comb. }\end{array}$ & $\begin{array}{c}\text { Comb } \\
4\end{array}$ \\
\hline 0,5 & 954 & 299,00 & 318,39 & $-0,4 \%$ & $-0,4 \%$ \\
0,25 & 2356 & 300,31 & 319,71 & $-0,1 \%$ & $-0,1 \%$ \\
0,125 & 6584 & 300,75 & 320,15 & $0,0 \%$ & $0,0 \%$ \\
0,0625 & 20636 & 300,86 & 320,27 & - & - \\
\hline
\end{tabular}


ISSN: $1415-7314$

ISSN online: $2317-6717$

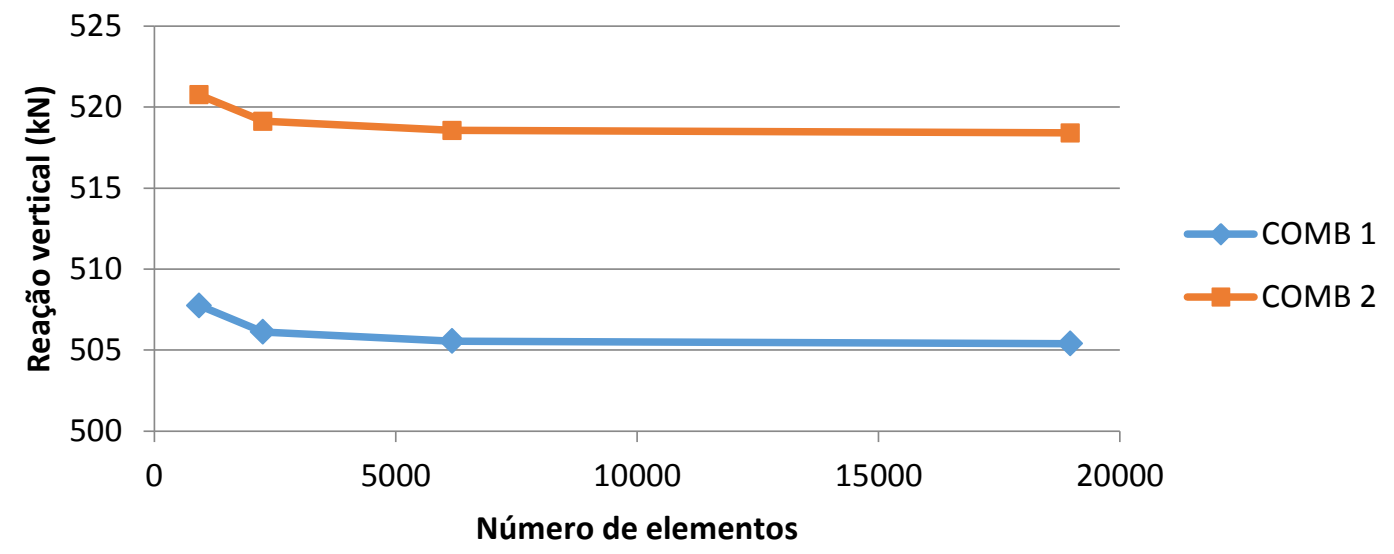

Figura 9. Análise de independência da malha paras as combinações 1 e 2 .

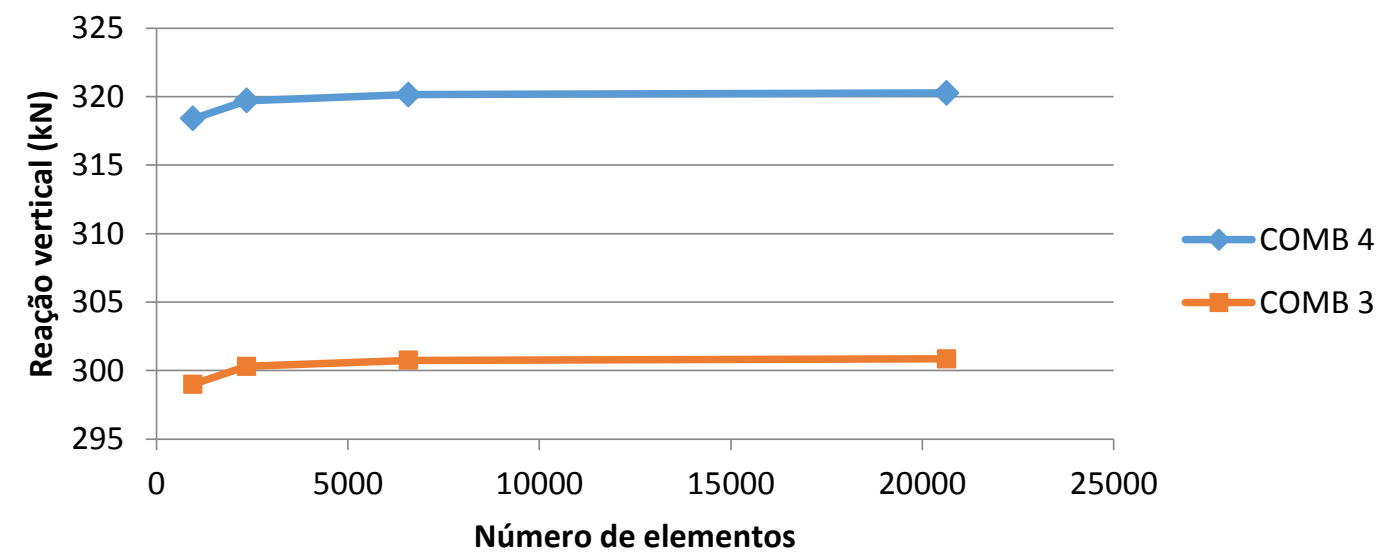

Figura 10. Análise de independência da malha paras as combinações 3 e 4 .

\subsection{Verificação do modelo}

De acordo com Longo (2006), o controle da qualidade do projeto é fundamental em todos os setores da engenharia. Esse controle, que deve levar em consideração a verificação dos resultados computacionais, consiste em verificar se o projeto atende às exigências de qualidade a ele requeridas. A verificação pode ser feita por diversas formas, como por exemplo, os métodos aproximados, a visualização das saídas gráficas e a comparação com outros projetos semelhantes, entre outras.

Neste trabalho, a verificação do modelo computacional construído no software ANSYS® foi realizada com a comparação dos resultados obtidos para a mesma estrutura com o software SAP2000, que consiste em uma plataforma integrada para análises estruturais e projetos de engenharia. Foram comparados os valores dos esforços axiais na base das vinte estacas para as combinações 2 e 4 . As figuras 11 e 12 apresentam a comparação desses resultados. 
ISSN: $1415-7314$

ISSN online: $2317-6717$

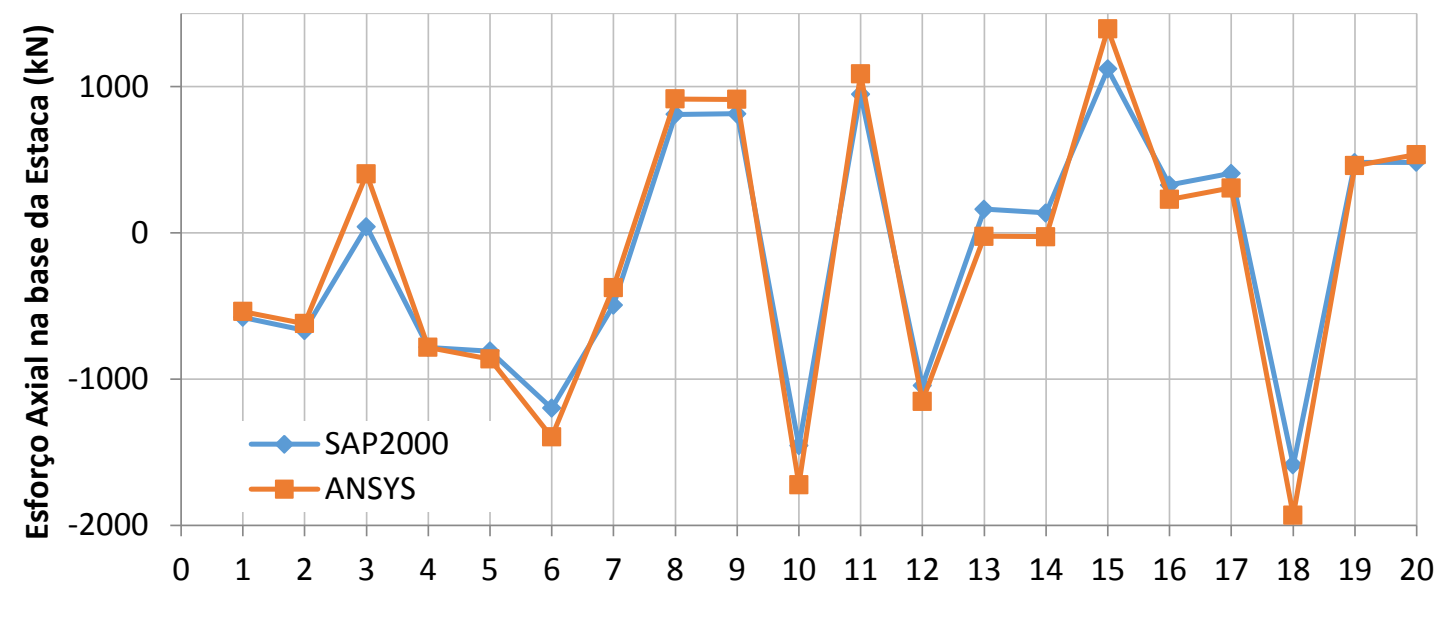

Estaca

Figura 11: Comparação dos resultados das reações axiais obtidos nos softwares ANSYS® e SAP2000 para a combinação 2 .

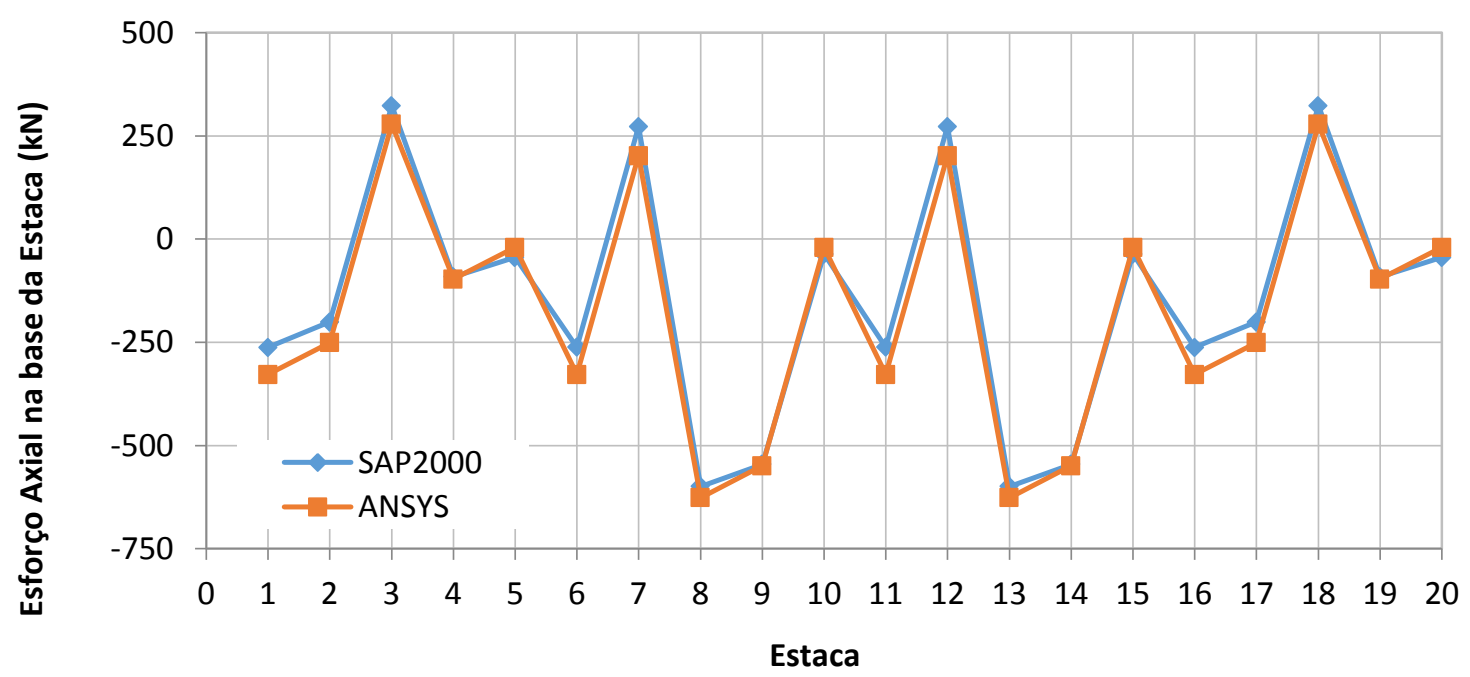

Figura 12: Comparação dos resultados das reações axiais obtidos nos softwares ANSYS® e SAP2000 para a combinação 4.

Apesar de terem sido encontrados valores bastante elevados de diferença percentual entre os dois modelos para algumas poucas estacas, nota-se que as séries obtidas apresentam distribuição e ordem de grandezas muito semelhantes, configurando o modelo utilizado neste trabalho como satisfatório.

\subsection{Análise probabilística - convergência}

Conforme dito anteriormente, a análise probabilística consiste em estudar a estrutura quando o carregamento varia, respeitando um determinado limite de variabilidade. Para cada simulação, o valor de cada carga é aleatoriamente selecionado e a solução é encontrada. Naturalmente, quanto mais simulações forem realizadas, mais combinações são feitas e melhores são os resultados. 
Faz-se necessário então um estudo de convergência similar à convergência da malha, porém agora para determinar quantas simulações são necessárias para obter um resultado satisfatório.

Além disso, foram comparadas as convergências do método de Monte Carlo direto (MCS) e o método Latin Hypercube (LHS). Inicialmente foram feitas 100 e 250 simulações e, a partir daí, com acréscimos de 250, foi-se até o número 2500 simulações, para ambos os métodos. As tabelas 7 e 8 mostram os resultados obtidos por cada um dos métodos:

Tabela 7: Convergência do método Monte Carlo Direto (MCS).

\begin{tabular}{cccc}
\hline \multirow{2}{*}{$\mathrm{N}^{\circ}$ de simulações } & \multicolumn{3}{c}{ Reação Vertical } \\
\cline { 2 - 4 } & $\begin{array}{c}\text { Média } \\
(\mathrm{kN})\end{array}$ & $\begin{array}{c}\text { Diferença } \\
\text { Percentual }\end{array}$ & $\begin{array}{c}\text { Desvio Padrão } \\
(\mathrm{kN})\end{array}$ \\
\hline 100 & 375,45 & - & 95,13 \\
250 & 377,84 & $0,633 \%$ & 89,85 \\
500 & 374,45 & $-0,905 \%$ & 89,95 \\
750 & 376,67 & $0,589 \%$ & 90,47 \\
1000 & 375,09 & $-0,421 \%$ & 90,07 \\
1250 & 376,08 & $0,263 \%$ & 91,25 \\
1500 & 374,49 & $-0,425 \%$ & 90,27 \\
1750 & 374,93 & $0,117 \%$ & 90,73 \\
2000 & 374,26 & $-0,179 \%$ & 90,91 \\
2250 & 374,44 & $0,048 \%$ & 90,99 \\
2500 & 375,17 & $0,195 \%$ & 91,21 \\
\hline
\end{tabular}

Tabela 8: Convergência do método Latin Hypercube (LHS).

\begin{tabular}{cccc}
\hline \multirow{2}{*}{ N $^{\mathrm{o}}$ de simulações } & \multicolumn{3}{c}{ Reação Vertical } \\
\cline { 2 - 4 } & $\begin{array}{c}\text { Média } \\
(\mathrm{kN})\end{array}$ & $\begin{array}{c}\text { Diferença } \\
\text { Percentual }\end{array}$ & $\begin{array}{c}\text { Desvio Padrão } \\
(\mathrm{kN})\end{array}$ \\
\hline 100 & 374,97 & - & 92,99 \\
250 & 375,27 & $0,080 \%$ & 91,94 \\
500 & 375,25 & $-0,005 \%$ & 90,78 \\
750 & 375,35 & $0,027 \%$ & 90,16 \\
1000 & 375,26 & $-0,024 \%$ & 89,58 \\
1250 & 375,26 & $0,000 \%$ & 90,79 \\
1500 & 375,26 & $0,000 \%$ & 89,46 \\
1750 & 375,32 & $0,016 \%$ & 90,69 \\
2000 & 375,30 & $-0,005 \%$ & 90,44 \\
2250 & 375,28 & $-0,005 \%$ & 90,40 \\
2500 & 375,28 & $0,000 \%$ & 90,51 \\
\hline
\end{tabular}

Desta forma, fica clara a vantagem de utilizar-se o método Latin Hipercube, visto que a convergência ocorre com um número muito menor de simulações, conforme mostram as figuras 13 e 14. 
ISSN: $1415-7314$

ISSN online: 2317-6717

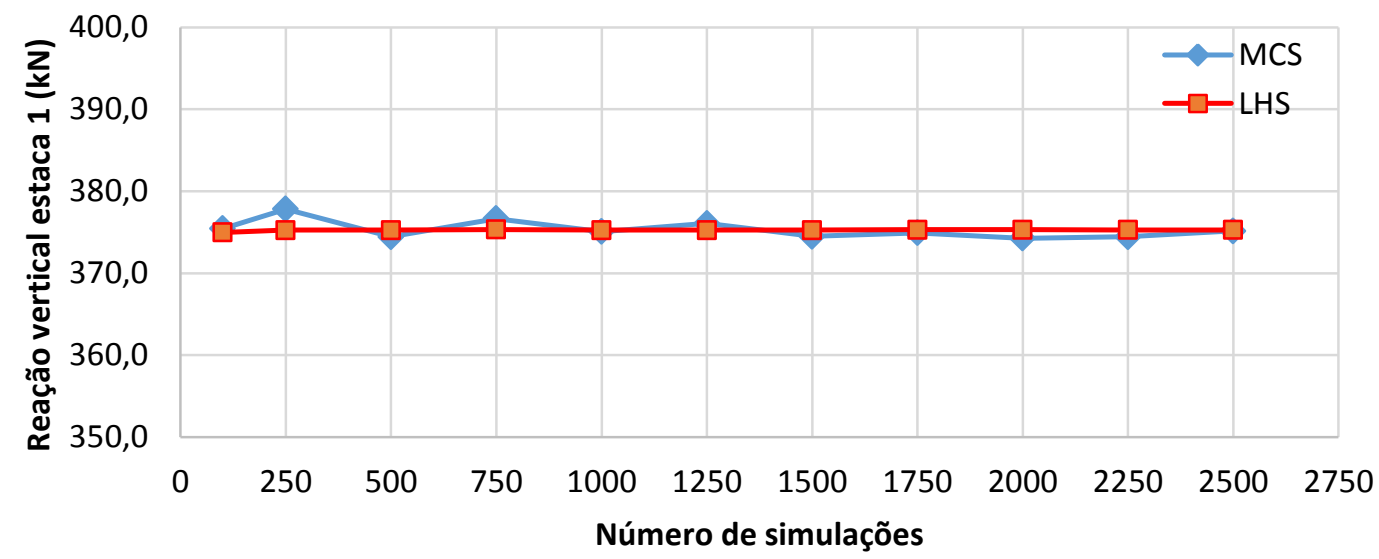

Figura 13: Comparação entre os valores médios de cada método probabilístico.

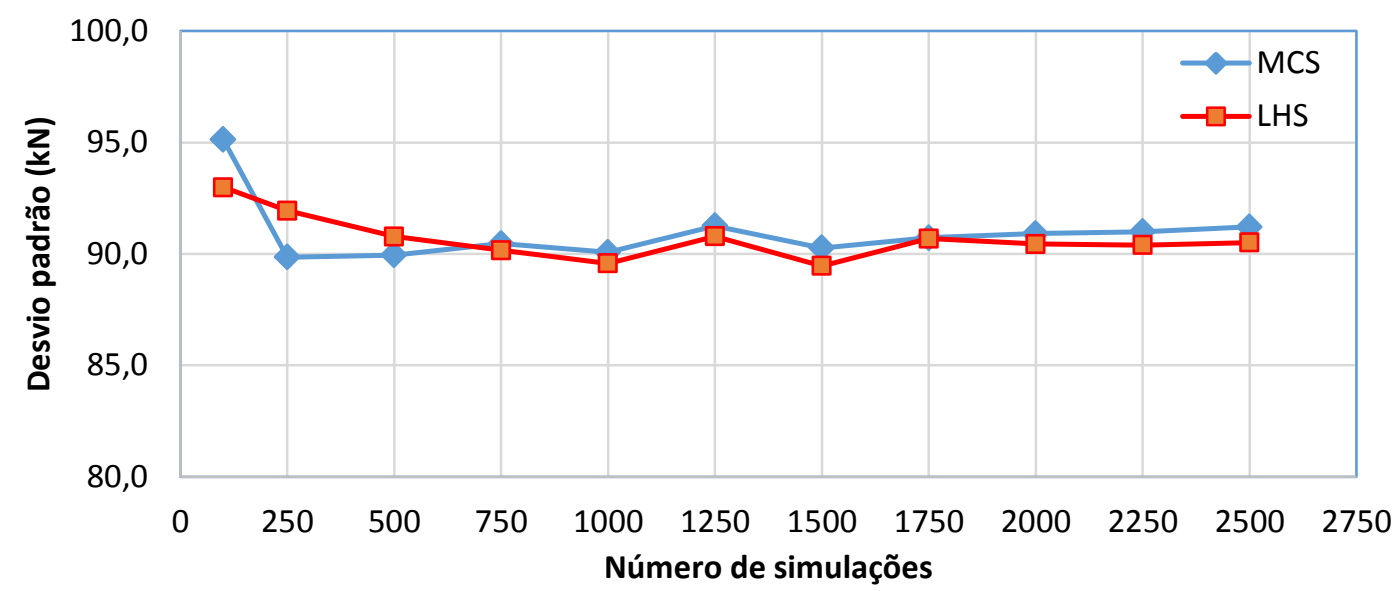

Figura 14: Comparação entre o desvio padrão de cada método probabilístico.

Após o teste de convergência dos métodos de análise probabilística utilizados neste trabalho, determinou-se que 500 simulações com o Latin Hypercube são suficientes para obter resultados satisfatórios.

\subsection{Distribuição de probabilidade do carregamento}

Uma vez determinado o número de simulações e o tamanho do elemento da malha, pode-se finalmente realizar a análise probabilística da estrutura. Conforme descrito anteriormente, foram feitas quatro combinações de carregamentos: duas para o dolfim de amarração e duas para o dolfim de atracação. Para cada combinação foram realizadas 500 simulações e ao final foi lido o valor da reação vertical para a estaca mais carregada em cada caso. A estaca mais carregada em cada tipo de estrutura foi obtida pela análise determinística das estruturas sob efeito das ações características consideradas, processo que também foi feito através do software ANSYS®.

No caso do dolfim de amarração, a estaca 18 foi a mais solicitada nas duas combinações, enquanto que para o dolfim de amarração, a estaca 8 apresentou os maiores esforços. 


\subsubsection{Gráficos de probabilidade}

Os gráficos mais comuns na análise de distribuições normais são o quantil - quantil, o percentil - percentil e a função distribuição acumulada. Além de determinar a normalidade de uma determinada distribuição, estes gráficos podem fornecer estimativas da média e desvio padrão se a distribuição for normal ou próxima à normal (Thode, 2002).

O software ANSYS ${ }^{\circledR}$ oferece a opção de plotagem da função distribuição acumulada (FDA). Nesse gráfico, os valores observados são plotados contra o desvio padrão e, caso os pontos estejam próximos a uma reta, pode-se inferir que a distribuição é normal (D'agostino \& Stephens, 1986).

Além disso, o próprio histograma oferece uma boa impressão a respeito da distribuição. Junto com a FDA, é possível determinar com boa precisão se a distribuição analisada é normal.

\subsubsection{Resultados da análise probabilística}

Nas figuras 15 e 16 são mostrados os resultados das análises probabilísticas na forma de histogramas das reações verticais nas estacas de cada uma das combinações analisadas.

Uma rápida leitura dos histogramas indica que a distribuição das reações é, assim como cada um dos carregamentos, uma distribuição normal.

Não obstante, através dos gráficos FDA mostrados nas figuras 17 e 18, pode-se ter mais clareza a respeito da normalidade da curva.
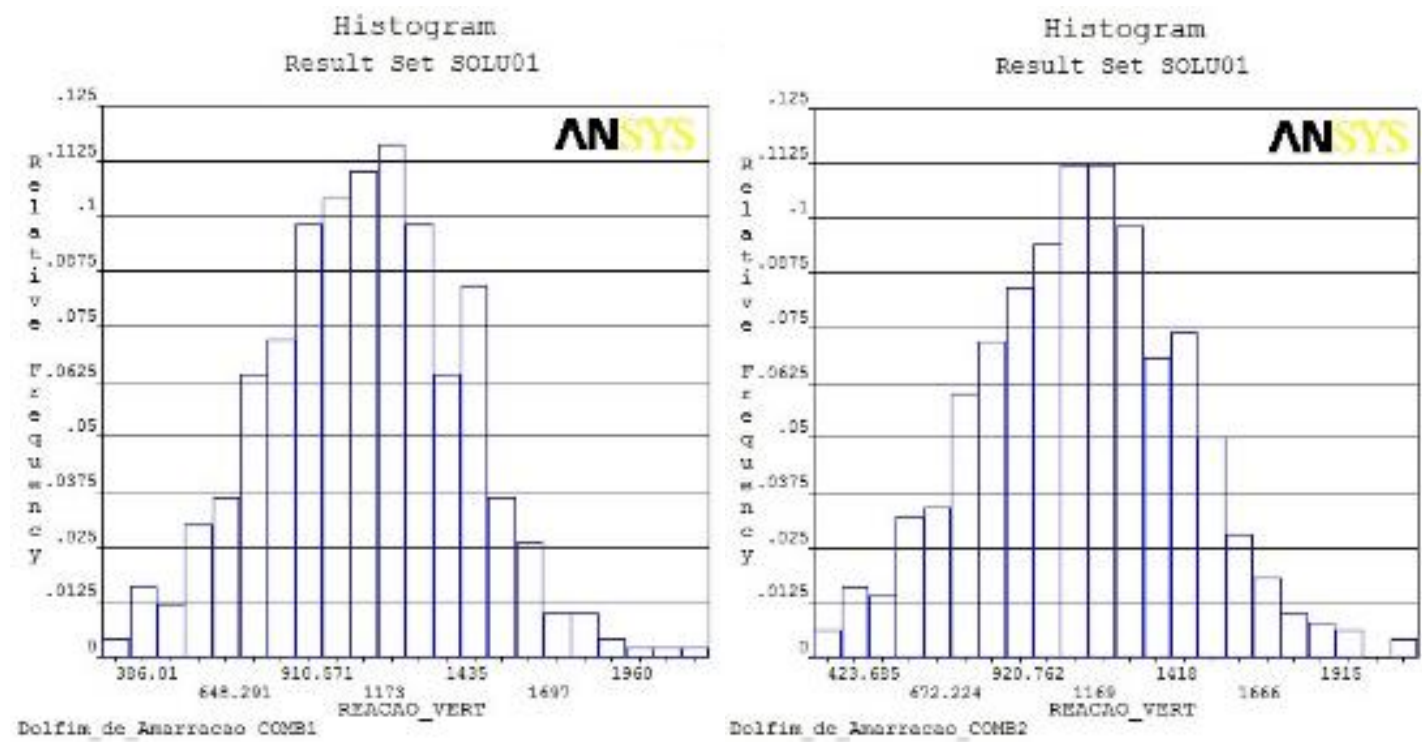

Figura 15. Histogramas das combinações 1 e 2. 
ISSN: $1415-7314$

ISSN online: 2317-6717
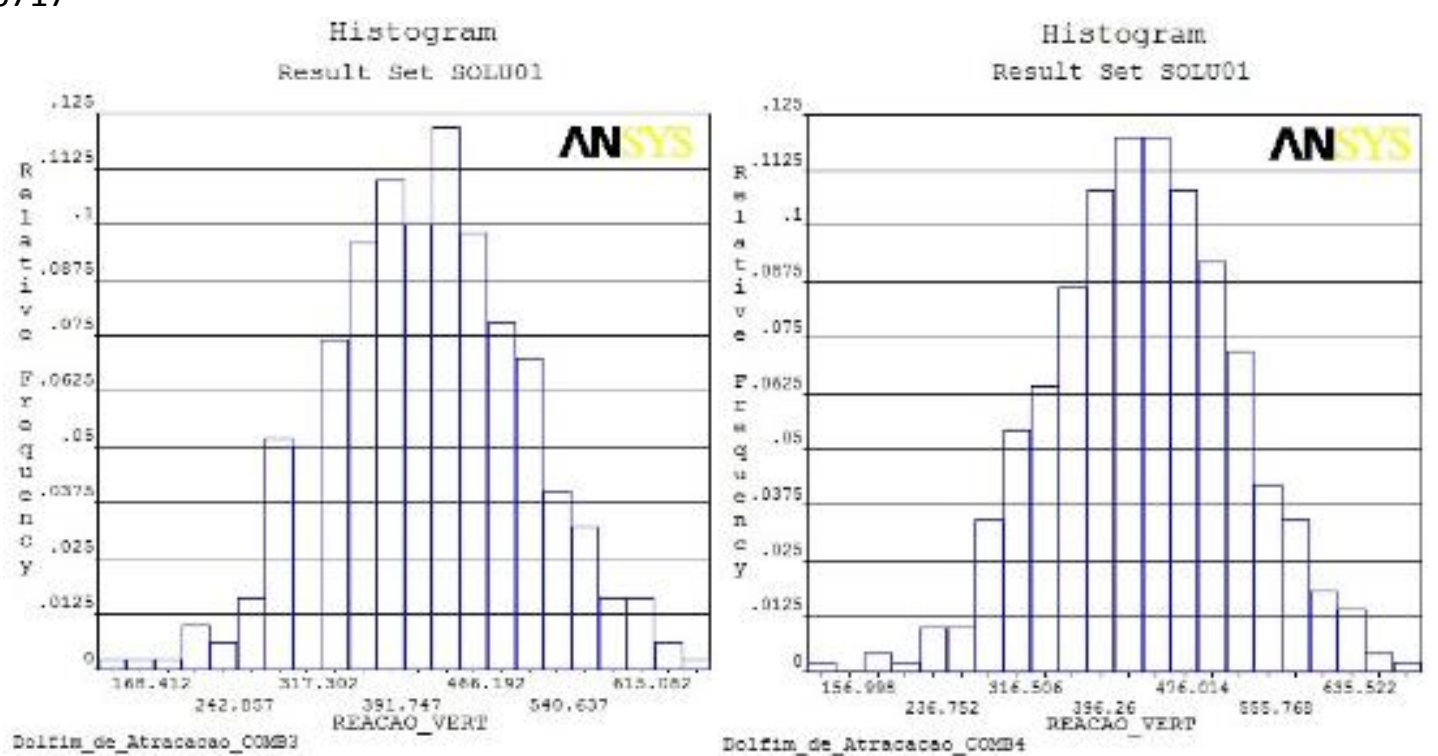

Figura 16: Histogramas das combinações 3 e 4.
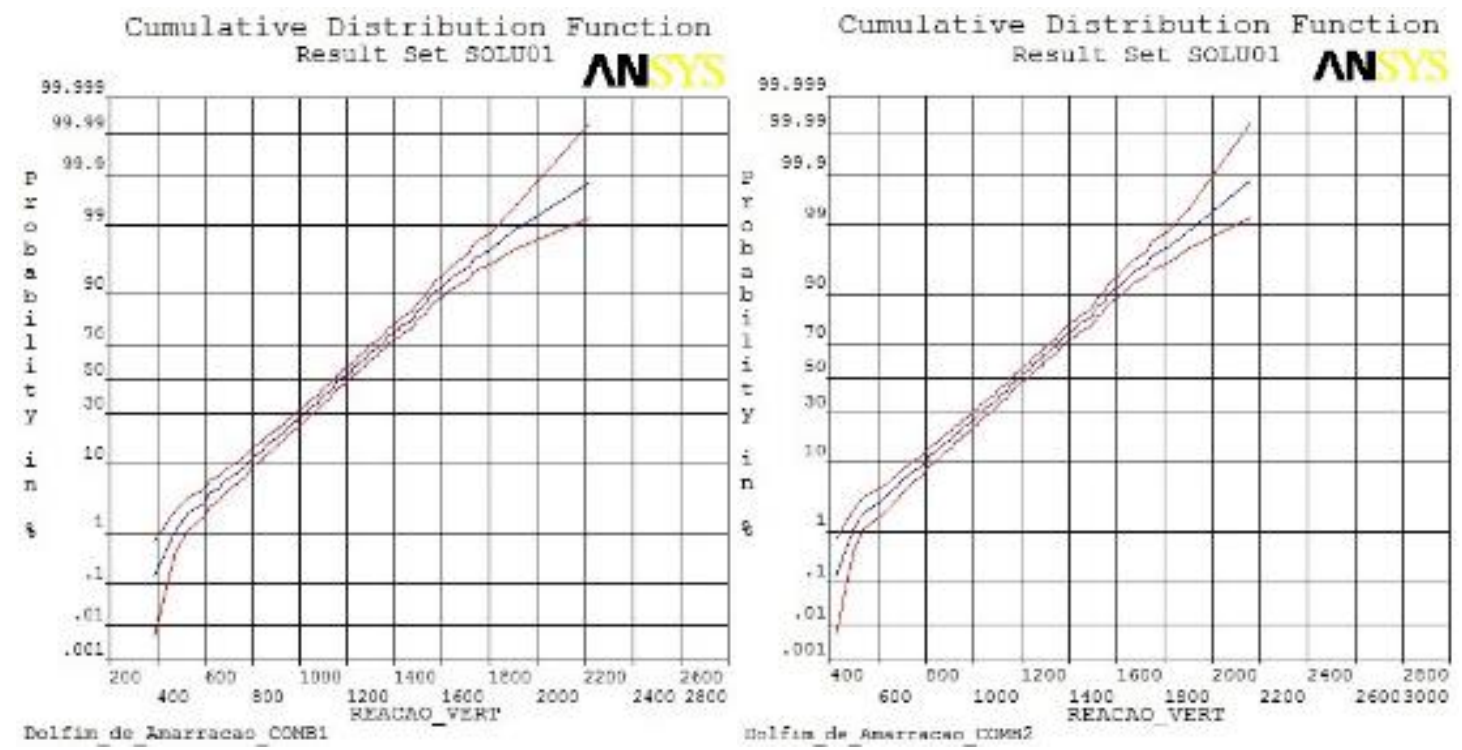

Figura 17: Função distribuição acumulada das combinações1 e 2.
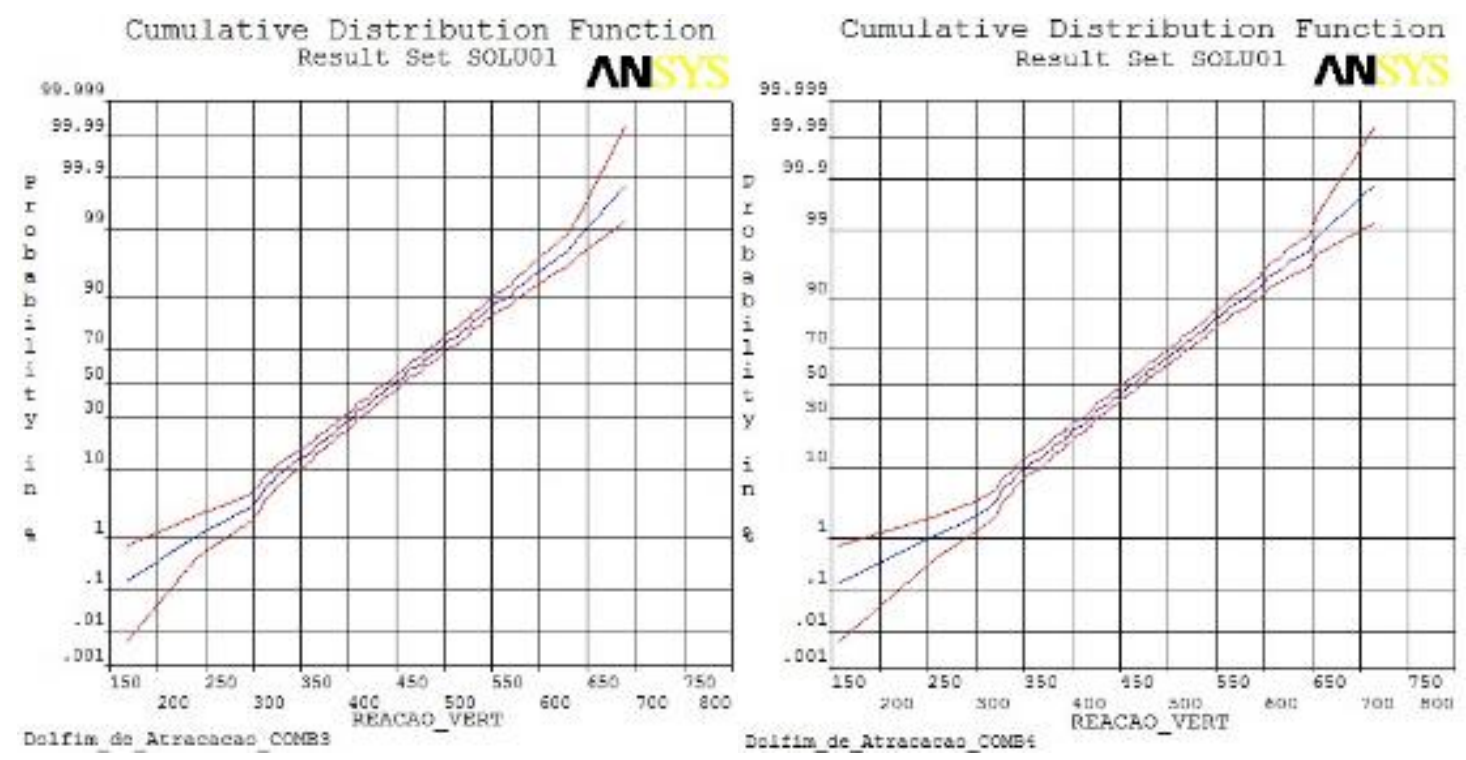

Figura 18: Função distribuição acumulada das combinações 3 e 4.

ENGEVISTA, V. 19, n.2 , p. 459-481, Maio 2017.

Todos as informações e direitos sobre o presente artigo são de total e única responsabilidade do(s) autor(es). 
Conforme mencionado em 3.1.5, quando a FDA se aproxima de uma reta é razoável considerar a distribuição como sendo normal. Nesse caso, as quatro situações apresentam pontos que podem ser aproximados a uma reta e, portanto, conclui-se que a distribuição de probabilidade da reação vertical das estacas é distribuída normalmente.

Por fim, procurou-se determinar quais os valores da probabilidade de as reações verticais obtidas através das análises probabilísticas $\left(\mathrm{F}_{\mathrm{p}}\right)$ ultrapassassem as reações verticais obtidas pela análise determinística dasestruturas $\left(\mathrm{F}_{\mathrm{k}}\right)$, ou seja, a verificação quantitativa de $\mathrm{P}\left(\mathrm{F}_{\mathrm{p}}>\mathrm{F}_{\mathrm{k}}\right)$.

De acordo com Larson \& Farber (2010), para uma distribuição normal de média $\mu$, desvio padrão $\sigma$ e um determinado valor $x$ abaixo da curva normal, tem-se que o z-escore (medida de posição que indica o número de desvios padrão de um valor qualquer a partira da média) é igual a:

$$
\mathrm{z}=\frac{\mathrm{x}-\mu}{\sigma}
$$

Para a combinação 1 , por exemplo, a estaca 18 - a mais carregada na análise determinística - apresentou uma reação vertical de 1858,70 kN. De acordo com os dados obtidos na análise probabilística para a mesma combinação, essa estaca apresentou reação vertical média igual a $1177,40 \mathrm{kN}$, com desvio padrão de 310,10 kN. Logo, para $x=1858,70$, o z-escore é obtido pela equação 5 e possui valor de 2,20, e a área abaixo da curva normal é igual a 0,9861 , ou seja, 98,61\% dos valores calculados estão abaixo do valor $x$. Conclui-se então que, de acordo com a análise probabilística executada, existem $1,39 \%$ de chance de que a reação vertical atinja valores maiores do que o valor calculado através da análise determinística. A tabela 9 apresenta os resultados deste cálculo para cada uma das quatro combinações:

Tabela 9: Probabilidades de ultrapassagem dos valores característicos na análise probabilística

\begin{tabular}{ccccc}
\hline \multirow{2}{*}{ Parâmetro } & Combinação & Combinação & Combinação & Combinação \\
& 1 & 2 & 3 & 4 \\
\hline$\mu(\mathrm{kN})$ & 1177,4 & 1190,5 & 448,8 & 464,2 \\
$\sigma(\mathrm{kN})$ & 310,1 & 308,77 & 87,461 & 87,824 \\
$\mathrm{x}(\mathrm{kN})$ & 1858,70 & 1873,90 & 590,77 & 606,17 \\
$\mathrm{z}-\mathrm{escore}$ & 2,20 & 2,21 & 1,62 & 1,62 \\
$\mathrm{P}\left(\mathrm{F}_{\mathrm{p}}>\mathrm{F}_{\mathrm{k}}\right)$ & $1,39 \%$ & $1,36 \%$ & $5,26 \%$ & $5,26 \%$ \\
\hline
\end{tabular}

\section{Conclusão}

Neste trabalho foi realizada uma análise probabilística com o objetivo de determinar a distribuição das reações verticais das estacas de dois dolfins de amarração e de atracação, considerando a variabilidade das cargas atuantes na estrutura. Com os resultados da análise probabilística, foi obtida a probabilidade de estas reações superarem os esforços característicos utilizados na análise convencional. 
O modelo computacional gerado com o software ANSYS® permitiu o cálculo dos esforços nos elementos estruturais de interesse. Para tanto, foi utilizado o método dos elementos finitos para a discretização das estruturas, com os resultados se mostrando satisfatórios para elementos de placa e viga com tamanhos de $0,50 \mathrm{~m}$. Para verificação do modelo computacional gerado foi feita uma comparação com os resultados obtidos na plataforma SAP 2000.

A partir dos dados obtidos nas avaliações de convergência dos métodos estatísticos utilizados, de Monte Carlo e Latin Hypercube, foi possível verificar a velocidade de convergência de ambos os métodos para a média e o desvio padrão dos valores dos esforços das estacas mais carregadas. Para a média, foi notado que o método Latin Hypercube apresenta convergência satisfatória com um número relativamente pequeno de simulações, ao passo que o método de Monte Carlo pode apresentar variações indesejáveis nesses valores mesmo para números mais elevados de simulações. Já para o desvio-padrão ambos os modelos apresentaram convergências semelhantes, com o método Latin Hypercube apresentando um comportamento inicial de melhor convergência, porém se parecendo com o do método Monte Carlo à medida que o número de simulações aumenta. Portanto, verificou-se que a utilização do Latin Hypercube para a coleta de amostras mostrou-se mais eficiente para o caso em estudo.

As simulações foram realizadas com os carregamentos atuantes nas estruturas - peso próprio, sobrecarga acidental, esforços de amarração e impacto- distribuídos normalmente em torno dos valores médios. Foi observado que a resposta analisada, a reação vertical na estaca mais carregada, também apresentou distribuição normal.

Após a realização das simulações, os resultados probabilísticos foram comparados com os resultados obtidos na análise determinística convencional e verificou-se que, para o dolfim de amarração, existe uma chance de aproximadamente $1,39 \%$ de que a estaca seja submetida a um esforço maior do que o valor utilizado no dimensionamento das estacas. Já para o dolfim de atracação, este valor chegou a 5,26\%.Deste modo, conclui-se que o dimensionamento de uma estrutura como a analisada neste trabalho realizado a partir de uma análise determinística, sem considerar a variabilidade das cargas atuantes, mostra-se suficiente para garantir a estabilidade e segurança da mesma.

Por fim, indica-se como base para estudos futuros a expansão da análise realizada neste trabalho para outros tipos de estruturas semelhantes, como cais de terminais de contêineres, de estaleiros e portuários em geral, outros tipos de carregamentos, como ações provenientes de equipamentos diversos operando sobre as estruturas e esforços provenientes da variação de temperatura, bem como a variação de características próprias dos dolfins, como a inclinação das estacas e as condições de vinculação dos elementos. Além disso, recomenda-se maiores estudos a respeito da distribuição dos carregamentos atuantes nessas estruturas com o intuito de obter parâmetros estatísticos que possibilitem análises probabilísticas mais precisas. 


\section{REFERÊNCIAS}

ALFREDINI, P., ARASAKI, E. 2009.Obras e gestão de portos e costas - A técnica aliada ao enfoque logística e ambiental. 2. ed. Editora Blucher. São Paulo. 776p.

ANSYS ${ }^{\circledR}$. User's Manual. v. 10.0 (version 10.0). 2005. Swanson Analysis System Inc. Houston.

ARAÚJO, J. M. 2010. Curso de Concreto Armado. v. 1. 3. ed. Editora Dunas. 257p.

ASSOCIAÇÃO BRASILEIRA DE NORMAS TÉCNICAS. NBR 6118:2014 - Projeto de Estruturas de Concreto - Procedimento. 2014.

CORREA, S. M. B. B. 2003.Probabilidade e Estatística. $2^{\mathrm{a}}$ ed. Belo Horizonte: PUC Minas Virtual, 2003. $116 \mathrm{p}$.

D’AGOSTINO, R. B; STEPHENS, M. A. 1986. Goodness-of-fit techniques. Marcel Dekker Inc. New York.

GERDAU S.A. Perfis Estruturais GERDAU - Tabela de Bitolas.2016.Available: https://www.gerdau.com/br/pt/produtos/perfis-estruturais-gerdau\#ad-image-0

GOMES, C. M. A. 2013. Aplicação do método de Monte Carlo ao estudo da influência dos dados de entrada na simulação energética de edifícios escolares. 139 p. Dissertação de Mestrado, Instituto Politécnico de Viseu. Viseu.

HENDRICKS, W. A.; ROBEY, K. W. 1936. The Sampling Distribution of the Coefficient of Variation. Mathematic Statistics, v 7, n 3, p 129 - 132.

JOINT COMMITTEE ON STRUCTURAL SAFETY. 2000. JCSS Probabilistic Model Code parts I, II \&III. Dinamarca.

LONGO, H. I. A importância da verificação dos resultados do computador. Anais do XXXIV Congresso Brasileiro de Educação em Engenharia, 2006. p.9.52-9.63. 2006 Passo Fundo.

MARTHA, L. F. 2010. Análise de estruturas: conceitos e métodos básicos. Editora Elsevier. Rio de Janeiro. 524p.

MATTAR, F. N. 1992. Pesquisa de Marketing. Editora Atlas. São Paulo.

REH, S.; BELEY, J. D.; Mukherjee, S., Khor, E. H. 2006.Probabilistic finite element analysis using ANSYS. Structural Safety, 28, p. 17-43.

TEIXEIRA, G. M.; KESSLER, M.P.; MALISKA, C.R., 2009. Fontes de erro: identificar, quantificar e reduzir a intervalos aceitáveis. Artigo técnico.

Available:http://www.esss.com.br/blog/wp-

content/uploads/2009/09/ESSS_Artigo_Tecnico_21.pdf.

THODE, H. C. JR. 2002.Testing for normality. Marcel Dekker Inc. New York.

TSINKER, G. P. 2004.PortEngineering: Planning, Construction, Maintenance, and Security. Editora Wiley. Hoboken, New Jersey. 94p, 474p.

VEIGA, J. M. G. C. 2008. Métodos de análise das incertezas na verificação da segurança estrutural em Engenharia Civil. Julho de 2008. 299 p. Tese de Doutorado, Universidade do Porto, Porto.

VERSTEEGT, G. 2013.Berthingloads in structural design: validation of partial factors .Dissertação de mestrado, Delft University of Technology. Delft.

ZIENKIEWICZ, O. C.1977.The finite element method. McGraw-Hill Book Company (UK) Limited.3. ed. England. 